LUNAR SAMPLES

\section{SRC asks for More Moon}

\section{by our Astronomy Correspondent}

Applications by British scientists for samples from the next batches of Moon rock and dust are expected to be forwarded to NASA within the next few days, just as soon as the applications have received the stamp of approval of the Space Policy and Grants Committce of the Science Research Council. Last week the applications were vetted by the Lunar and Planetary Panel, the committee of the SRC under the chairmanship of Professor K. Runcorn that deals with the lunar samples programme. It is believed that proposals from twenty-five groups will be forwarded to NASA, including experiments suggested by groups which properly come under the Natural Environment Research Council, and by groups in government laboratories.

The SRC is of course the scientific agency in Britain with which NASA deals and through which all applications for lunar material have to be channelled. Fifteen teams in Britain were on the SRC list for receipt of samples from the Apollo 11 and Apollo 12 missions, so it seems that interest has widened considerably. But the SRC is not saying at this stage what new experiments are being proposed, or indeed who the experimenters are, although it appears that no out of the ordinary proposals have been put forward. It seems safe to assume that the samples will be subject to a similar battery of tests as before: mineralogical and petrological examination, elemental analysis, age determination, examination for organic chemicals, analysis of physical properties (notably magnetism and luminescence), and so on.

The applications are for samples of the material which will be returned by the remaining Moon missions, Apollos 14 to 19. But the Science Research Council believes that NASA will provide further opportunities to apply for samples as the Apollo programme develops.

Nevertheless, there is still concern among scientists in Britain that liaison between the SRC and NASA is not as good as it could be. Complaints that NASA is weak on giving advance notice of opportunities to participate in space experiments are common, although this seems to be a problem that also afflicts scientists in the United States. But with interest in lunar and planetary science booming in Britain, and the omens good for the proposed school of planetary science at Lancaster University, people are looking for closer contact with the American programme. One idea which has been put forward by NASA is for a British scientist nominated by the SRC to work at Houston taking an active part in the Manned Spacecraft Center. The SRC refuses to comment because the NASA offer is apparently unofficial at present. People in the planetary sciences were hoping that the SRC would jump at the chance.

\section{POLLUTION}

\section{Booms Banned; Exhausts Exempted}

NoISE and smoke are the chief targets of the White Paper on the environment published by the British government on May 28. If the government is re-elected, commercial supersonic flights will not be allowed to make sonic booms overland, and existing aircraft may be required to be quieter in taking off and landing. Heavy road vehicles will have to be checked annually for noise, and all new vehicles will need to be fitted with a device to reduce emissions of unburned hydrocarbons. More industrial processes will come within the scope of the Alkali Act, which controls air pollution, and reluctant local authorities in badly polluted areas will be compelled to ban domestic coal fires. Together with proposals for cleaning up land and water, these plans for legislation would be put into action during the lifetime of the next government, the Secretary of State for Local Government and Regional Planning, Mr Anthony Crosland, said when he introduced the White Paper (The Protection of the Environment, HMSO, London, 15p).

By deciding to outlaw the sonic boom, the government has reduced the potential sales of the Concorde (although the British Aircraft Corporation has always assumed in its sales projections that Concorde will be banned from flying overland), and other countries beneath the transatlantic air routes from Europe have already indicated that they intend to ban supersonic overflying. Without a ban by Britain, Concorde might sell 80 per cent more than the 250 planes expected to be sold by 1980 . But those who have been complaining that the Concorde project puts profits before people are heartened by the decision, and the Noise Abatement Society talks of the proposal to ban overland commercial flights as a "splendid achievement", even though supersonic test flights over Britain this summer are to continue.

The proposals for clean air have been greeted with more scepticism. The trouble is that next winter there will not be enough smokeless fuel to go round because the output of gas coke has fallen now that natural gas is widely used, and many smoke control orders are being suspended to allow people to heat their houses with coal. As a result, the White Paper admits that the clean air programme will have to be delayed. This does not please the director of the National Society for Clean Air, Rear-Admiral P. G. Sharp, who is not confident that government plans for keeping open a few uneconomic gas works will be enough to solve the fuel shortage quickly. He would like to see more encouragement now instead of later as the White Paper implies, for people to use electricity, gas or oil instead of solid fuels. $\mathrm{He}$ is also disappointed that there are no plans for reducing the carbon monoxide content of vehicle exhausts-Mr Crosland's view is that the British climate does not warrant such drastic measures as are necessary, for example, in Los Angeles, even though the Economic Commission for Europe has recommended a general reduction of carbon monoxide emissions.

On waste disposal and water pollution, the government will let itself be guided by some half-dozen official reports which are due to appear within the next year, but it promises eventually to undertake a national clean rivers programme and will, in any case, be restructuring the water and sewage industry when the pattern of local government is reorganized. The White Paper is more specific about the penalties that should be imposed for pollution offences, which at the moment are absurdly small ( $£ 100$, for example, for illegal discharges into rivers). These fines, the White Paper says, should be "brought into line with the realities of modern life", and the recent Oil in 